\title{
Develando el caos: Débora Arango, la artista y su obra, DESDE LA PERSPECTIVA DE CORNELIUS CASTORIADIS
}

\section{Unveiling Chaos: Débora Arango, the Artist and her Work, from the Perspective of Cornelius Castoriadis}

\author{
Jaime A. Gómez Prada* \\ DOI: http://dx.doi.org/10.29043/liminar.v19i2.844
}

\begin{abstract}
Resumen: En este artículo se analiza la vida y obra de la pintora colombiana Débora Arango (1907-2005) desde los planteamientos del filósofo greco-francés Cornelius Castoriadis (1922-1997). Se examinan las actuaciones de la artista y obras concretas a la luz del proyecto de autonomía social e individual que enmarca el trabajo del autor, y bajo la mirada particular que sobre el arte plasmara en su texto Ventana al caos. Este ensayo representa un intento por comprender la conexión que une a un creador con su obra, siguiendo un caso específico: el de la artista plástica Débora Arango.
\end{abstract}

Palabras clave: Débora Arango, Cornelius Castoriadis, autonomía y heteronomía, arte y caos.

Abstract: This article analyzes the life and work of the Colombian painter Débora Arango (1907-2005) from the perspective of the Greek-French philosopher Cornelius Castoriadis (1922-1997). The life of the artist and her works are examined in light of certain ideas, such as the project of social and individual autonomy that frames Castoriadis's work, and his particular approach regarding art, which he explored in the text Window into Chaos. This article endeavors to understand the connection that unites a creator with his/her work, examining a specific case study, i.e., the plastic artist Débora Arango.

Key words: Débora Arango, Cornelius Castoriadis, autonomy and heteronomy, art and chaos.

\footnotetext{
* Jaime A. Gómez Prada. Doctor en Ciencias Sociales y Humanísticas por el Centro de Estudios Superiores de México y Centroamérica de la Universidad de Ciencias y Artes de Chiapas, México. Temas de especialización: estética e historia social del arte, relación arte/vida, arte del siglo XX y arte latinoamericano. Correo electrónico: jagopra@gmail. com. ORCID: https://orcid.org/0000-0001-7227-2724
}

Enviado a dictamen: 21 de septiembre de 2020

Aceptación: 16 de febrero de 2021 


\section{Introducción}

$\mathrm{D}$ ébora Arango (1907-2005) forma parte de ese grupo de mujeres latinoamericanas que, durante el siglo XX y en diferentes campos, lucharon por el reconocimiento de la mujer en igualdad de derechos. Su ocupación fue el arte. No fue propiamente una activista, fue una creadora que por esta vía, en medio del rechazo de una sociedad acentuadamente tradicionalista, católica, patriarcal y machista, ejemplificó de manera contundente el potencial que puede desplegar el ser humano cuando, desde su quehacer, asume su emancipación y su capacidad de transgredir lo establecido.

Nos referimos a una pintora colombiana nacida en Medellín; una vida marcada por la pasión artística, la determinación, la censura y el reconocimiento tardío. Abundante material se ha escrito acerca de su vida y obra, sin embargo, consideramos que aún no se ha profundizado lo suficiente en el acercamiento conjunto a la persona y a su arte en aras de intentar comprender la conexión que les une, y por esta ruta abonar a su comprensión integral. Con este texto nos proponemos realizar una aproximación que apunte en tal dirección, apoyándonos en los planteamientos del filósofo greco-francés Cornelius Castoriadis (1922-1997), quien, desde la defensa del proyecto de autonomía que enmarca su trabajo, aporta, en el ensayo Ventana al caos, un enfoque del arte como mirada al abismo, como develación del caos que nos habita, como creación de un cosmos que da forma a ese sinfondo.

En este abordaje, inicialmente nos situamos en el caso de Arango, describiendo los sucesos más relevantes de su vida y su obra, como también el contexto en el que se desarrolla. Luego, nos acercamos de manera condensada al vasto y complejo pensamiento castoridiano, deteniéndonos en los conceptos de autonomía, heteronomía, significaciones imaginarias sociales e imaginación radical, pilares claves de su propuesta. Seguidamente nos concentramos en Ventana al caos para conocer las ideas del autor en torno al arte, eje de este trabajo. Para finalizar, damos paso a nuestra propuesta: intentar leer el vínculo entre Arango y su obra desde la perspectiva intelectual de Castoriadis.

\section{Débora Arango: el ser humano y su obra}

Débora Arango nació en Medellín (Antioquia, Colombia) en el año de 1907 en una numerosa familia acomodada, en la que siempre encontró el apoyo necesario para el cultivo de su pasión por la pintura, interés que descubriría desde sus primeros estudios en una institución de orientación religiosa católica femenina. Su formación artística inicial la realiza con dos pintores destacados de su entorno y con reconocimiento nacional, ambos con formación en Europa. Inicia en 1932 con Eladio Vélez (1897-1967), con quien aprende sobre el dibujo, la acuarela y la técnica del retrato. Luego, en 1935 decide trabajar bajo la tutela de Pedro Nel Gómez (1899-1984), pionero de la pintura mural en Colombia. Con este último, Arango encontró lo que buscaba luego de considerar que había cumplido una etapa con Vélez, que era preciso superar, toda vez que, más allá de la copia de objetos y modelos propia del método que allí se trabajaba, sentía que "necesitaba crear, interpretar la naturaleza" (Laverde y Rojas, 1986:42) y fue esto lo que encontró en Gómez: "crear, combinar: soñaba con realizar una obra que no estuviese limitada a la inerte exactitud fotográfica de la escuela clásica" (Londoño, 1985:3-4). Es en esta etapa en la que Arango, motivada por el maestro Gómez, incursiona en la pintura de desnudos femeninos, temática que se volvería capital en su obra. Las palabras de Arango dejan ver la afinidad que en su momento encontró con el muralista, y la manera como sus planteamientos van en cierto modo marcando el rumbo de su propuesta plástica: "los artistas que comulgábamos con la escuela de Pedro Nel Gómez, vamos alejándonos de los viejos moldes y nos inclinamos cada vez más hacia la concepción modernista de la pintura revolucionaria, del arte destinado a interpretar el anhelo de las masas" (Londoño, 1985:4). ${ }^{1}$

Como complemento a su preparación, en 1946 Arango viaja a México en vista de su interés por la pintura mural, después, en la década de los cincuenta se desplaza a España (1954) para acercarse al arte europeo y tomar clases en la Academia de San Fernando en Madrid, por último, en 1960 estudia cerámica en Inglaterra. 
Antes de continuar, es preciso situarnos en el contexto histórico-social y artístico en el que tiene lugar la creación de Arango. Si bien estamos ante una persona que vive casi la totalidad del siglo XX, nos detendremos en la primera mitad de la centuria, dado que es en esta etapa en la que lleva a cabo su formación inicial y cuando se da a conocer en el ámbito artístico colombiano. Lo primero que debe resaltarse es que Arango nace y vive en Medellín, la segunda ciudad más importante del país, una urbe que, como lo anota Oscar Roldán-Alzate, era en aquellos tiempos "de naturaleza confesional", un lugar en el que, bajo una lógica tradicionalista, "la estructura católica hablaba al oído de las comandancias políticas de turno, las que a su vez llevaban a firme ejecución sus designios" (MAMM, 2012:14). ${ }^{2}$

Colombia en la primera mitad del siglo XX es un país marcado por el tránsito de una hegemonía conservadora que ostentó el poder por casi cincuenta años (1885-1930) hacia la denominada República Liberal que gobierna desde 1930 hasta 1946, un período de tiempo en el que el ascenso de la polarización bipartidista se convierte en terreno fértil para el desencadenamiento de una ola de violencia política que afectaría al país, y que entre 1946 y 1960 resultó en la muerte de aproximadamente doscientas cincuenta mil personas, muchos de ellos adversarios políticos en la Colombia rural y en los poblaciones retiradas de los principales centros urbanos. Son estos los tiempos de una Colombia agraria - que empieza su tránsito hacia la urbanización y la industrialización-, con graves problemas de pobreza y de concentración de la tierra en pocas manos, así como de agitación social, tiempos de consolidación de la clase obrera y la organización sindical (Palacios y Safford, 2002; Palacios, 2003; LaRosa y Mejía, 2013). ${ }^{3}$

En el terreno artístico, Débora Arango inicia su vida cuando la revolución estética, que a finales del siglo XIX se había gestado en Europa, empieza a desplegarse por distintos caminos en las primeras décadas del siglo XX, a través de las denominadas vanguardias históricas. En este período, el arte realizado en Colombia mantiene la impronta del academicismo heredado del siglo XIX, imperando la temática del paisaje, el denominado neocostumbrismo, las preocupaciones por la identidad y la búsqueda de lo propio. En los años treinta empiezan a producirse cambios relevantes en la tierra de Arango como los que señala el crítico y curador Álvaro Medina:
El paisaje quedó atrás y ganó terreno el querer ex- presarse a través de la figura humana, que se alargó o ensanchó según la sensibilidad de cada artista [...]. El rechazo de la proporción anatómica tenida por bella según el modo clásico europeo, tuvo su contraparte en el gusto por la práctica de un dibujo más expresivo. Adquirió importancia la mancha informal y el uso de una paleta que se vuelve autónoma y puede apartarse del color que localmente pueden tener los objetos (Medina, s.f.).

Será hacia la mitad del siglo cuando, según la crítica de la época, entran en el escenario colombiano nuevos artistas que logran con sus producciones una mayor comprensión de la estética moderna, tales como: Alejandro Obregón (1920-1992), Edgar Negret (1920-2012), Eduardo Ramírez Villamizar (1922-2004) y Fernando Botero (1932) (Traba, 1985).

No podemos dar por terminado este brevísimo recorrido sin recordar que los tiempos de Arango son también los del movimiento muralista mexicano, corriente surgida en los años veinte - México posrevolucionario - que tuvo un amplio impacto en la plástica de buena parte de América Latina. Cabe anotar aquí que el paso de Débora Arango por México en 1946 obedeció a su interés por aprender la técnica al fresco propia de la pintura mural, dada la fascinación que mostró por ese arte desde cuando conoció los murales que el maestro Pedro Nel Gómez estaba realizando en el Palacio Municipal de Medellín en 1935 (Londoño, 1997:148-156). Es indudable que su estancia en México, además de permitirle a Arango conocer las obras de los muralistas, también le posibilita el acceso al arte de la época en la tierra de Rivera, Orozco y Siqueiros (artistas como Rufino Tamayo, María Izquierdo, Frida Kahlo, etcétera).

El debut de Débora Arango se da en el Primer Salón de Artistas Profesionales de Medellín en 1939, una iniciación que dejaría ver que su obra no pasaría desapercibida. Gana el primer premio con la obra 
Hermanas de la caridad, pero la semilla de la polémica ya estaba sembrada: dos de las pinturas presentadas, los desnudos La amiga y Cantarina de la rosa, encenderían el debate, porque "escandalizaron a las personas más tradicionalistas y moralistas de la ciudad" (Londoño, 1997:67-92). ${ }^{4}$ Luego, en 1940, una exposición individual abierta en el Teatro Colón de Bogotá es clausurada por presiones de orden político promovidas desde la dirigencia conservadora, que veía en eventos de este orden - promovidos por un gobierno liberal - una amenaza de corrupción para los cimientos de la sociedad colombiana. Más adelante, en 1955, una muestra suya en el Instituto de Cultura Hispánica en Madrid es también cerrada por orden del gobierno franquista al día siguiente de la apertura. La obra de Débora Arango incomodaba (Londoño, 1997). ${ }^{5}$

La oposición siempre latente provendrá de dos flancos distintos; uno impregnado de juicios extraestéticos relacionados con la defensa de la moral, en el que se mezclan una sociedad tradicionalista, la pugna política liberal/conservadora, y la Iglesia; el otro de la mano de la crítica artística dominante en la primera etapa de su carrera, que veía en estas pinturas un estilo pesado y anticuado que no encajaba en la modernidad estética que se quería impulsar en el medio artístico colombiano de los años cuarenta y cincuenta. ${ }^{6}$

Tras soportar ser el epicentro de una controversia continua, en 1960 Arango decide retirarse de la vida pública, lo que no quiere decir que deje de pintar, solo que en adelante se aísla a trabajar en su residencia hasta mediados de los setenta, tiempo en que la crítica empieza a revalorarla. Su participación en exposiciones se abre paso nuevamente, pero esta vez en medio de un reconocimiento creciente (MAMM, 2012:138-163) ${ }^{?}$

Débora Arango muere en 2005 a los 98 años de edad. Deja una creación que le concede un lugar relevante en el grupo de artistas que forjaron los procesos de transformación y las rupturas del arte colombiano del siglo XX.

Con Arango nos encontramos ante una pintora para quien la belleza y la representación de las formas bajo los cánones tradicionales quedan relegados a un segundo plano, para dar paso a un trabajo en el que la libertad expresiva se hace notar no solo en los temas y las maneras de abordarlos, sino también en los aspectos formales: el color saturado, los contrastes fuertes, la pincelada libre, enérgica y evidente, el empleo de marcadas líneas irregulares que bordean las figuras, la tensión entre las imágenes, la agitación de las formas y la alteración respecto de los referentes naturales. La pintora no rechaza en sus obras la belleza, pero se permite mostrar la fealdad, la agitación, la distorsión, la desproporción, la malformación, la incomodidad, el dolor, la herejía, el agobio. ${ }^{8}$

En una época en la que en su medio no se esperaba que la mujer se dedicara profesionalmente al arte, y menos que se entregara, entre otros temas, a pintar desnudos - tal vez podría aceptarse que trabajara paisajes, retratos o bodegones-, Arango entra en escena con unos desnudos en los que las formas femeninas se hacen evidentes y se pronuncian, y además se muestran sin disimulo, en posiciones y formas que se refieren a mujeres reales, y en actitudes que denotan seres decididos a manifestar su libertad e independencia, su autonomía (por ejemplo en: Montañas [1940], Frinéo Trata de blancas [1940], Contrastes [1940], Madona del silencio [1944], Sin título. Boceto de estudio desnudo contemporáneo [1954]).

En adición a los desnudos, Arango con su pintura rescata a aquellos personajes marginados de la sociedad, especialmente a las mujeres, y los pone en primer plano, reivindicando su humanidad y su espacio en la sociedad. Asimismo, pone en evidencia la situación de maltrato, abuso e injusticia a la que era sometido un sector de la población, en medio de una sociedad hipócrita y acentuadamente desigual que cerraba los ojos ante una realidad cuya existencia no le era del todo desconocida. La artista desenmascara esta sociedad y le muestra su realidad sin maquillajes (por ejemplo en: Voceadores [1940], Amanecer o En el barrio [1940], Esquizofrenia [1940], Justicia [1944], Los que entran y los que salen [1944], La lucha del destino [1944], Tugurianos [1958]). Tal vez no pudiéramos expresarlo mejor que retomando sus propias palabras cuando dijo que sus "temas son duros, acres, casi bárbaros, por eso desconciertan a las personas que quieran hacer de la vida y de la naturaleza lo que en realidad no son" (MAMM, 1984:26). 


\section{Un acercamiento al pensamiento de Cornelius Castoriadis}

Intentar referirse al pensamiento de Cornelius Castoriadis de manera sintética no es tarea fácil dada la cuantía de textos que recogen su pensamiento y la complejidad del mismo. Estamos ante una propuesta centrada en la promoción de la autonomía individual y social como camino para la creación de la propia realidad, una opción que se hace posible a partir del ejercicio de la voluntad entendida como "[...] la dimensión consciente de lo que somos como seres vivos definidos por la imaginación radical, o sea, definidos como seres potencialmente creadores" (Castoriadis, 2008b:II, 42). Para este autor el ser humano es diferente en tanto tiene la posibilidad de instituirse como sujeto y como sociedad. ${ }^{9}$

Hacemos un primer acercamiento a estas ideas a partir de términos recurrentes en el trabajo de Castoriadis como son heteronomía y clausura, y sus correspondientes contrarios, autonomía y apertura, pilares de su propuesta. Con relación a la heteronomía, el autor la define, en el terreno de lo humano y lo histórico-social, como "el estado en que son dados de una vez por todas los principios, los valores, las leyes, las normas y las significaciones y en que la sociedad, o el individuo según los casos, no tiene ninguna posibilidad de obrar sobre ellos" (Castoriadis, 2008b:I, 171). También se refiere a la heteronomía a nivel individual, como "el dominio por un imaginario autonomizado que se arrogó la función de definir para el sujeto tanto la realidad como su deseo" y en términos generales como una "alienación" de tipo social (Castoriadis, 2008b:II, 27), es decir, una "ocultación del ser de la sociedad como autoinstitución a sus propios ojos, recubrimiento de su temporalidad esencial" (Castoriadis, 2008b:II, 98).

Contrario al término de heteronomía, encontramos en Castoriadis el término de autonomía, que se refiere a "una autoinstitución de la sociedad, autoinstitución [...] más o menos explícita: nosotros hacemos las leyes, lo sabemos, y somos pues responsables de nuestras leyes, de modo que debemos preguntarnos cada vez: ipor qué esta ley y no otra?", una sociedad que además de tener claro que ha sido la creadora de sus leyes, también "se ha instituido a fin de liberar su imaginario radical y de poder alterar sus instituciones por intermedio de su propia actividad colectiva, reflexiva y deliberativa" (Castoriadis, 2008b:II, 172). Lo anterior, llevado al plano de lo individual equivale al surgimiento de un individuo - autónomo- que está en capacidad de formularse la misma pregunta: "iEs justa esta ley?”, pero además, uno que puede atribuirse la facultad de debatir los modelos, los métodos, las costumbres, los hábitos, las creencias, la tradición cultural, en fin, todo aquello que determina el modo de vivir en el mundo que le rodea, es decir, controvertir el marco de significaciones en el que se está inmerso (Castoriadis, 2008b:I, 172; II, 100). En la autonomía individual castoridiana estamos frente a "un nuevo tipo de ser capaz de poner en tela de juicio las leyes mismas de su existencia" (Castoriadis, 2008b:I, 172).

Asociados con la heteronomía y la autonomía, mencionamos inicialmente los términos clausura y apertura. Al primero de ellos se refiere Castoriadis como una "clausura de sentido" (2008b:II, 164), que es para el autor "el rasgo característico de las sociedades fuertemente heterónomas" (2008b:II, 134), una clausura cuyo significado debe entenderse en el sentido matemático del término, es decir, en un mundo clausurado "toda pregunta susceptible de ser formulada en el mismo, o bien encuentra una respuesta en términos de significaciones dadas, o bien está planteada como desprovista de sentido" (Castoriadis, 2008b: II, 164). Un ejemplo de un mundo clausurado sería aquel de la religión, institución que le ofrece al ser humano un sentido, pero un sentido fundamentado en dogmas, cerrado e incuestionable, sin ningún espacio para la dimensión imaginaria del ser. En cuanto a la apertura, el autor la equipara con la autonomía, pero refiriéndola como una apertura ontológica, como "posibilidad de sobrepasar el cerco de información, de conocimiento y de organización que caracteriza a los seres autoconstituyentes como heterónomos” y que implica “alterar el 'sistema' de conocimiento y de organización ya existente [y] constituir su propio mundo según otras leyes" (Castoriadis, 2008:II, 76). Es en la apertura en donde el sujeto hace uso de su dimensión imaginaria y se abre a la posibilidad de resignificar lo dado. 
La revisión de definiciones que acabamos de hacer deja ver que el planteamiento de Castoriadis se orienta hacia el cuestionamiento de lo dado, es decir, el cuestionamiento de la institución de la sociedad — de cada sociedad-, que tiene que ver con la ruptura de la clausura de la significación, con la liberación del pensamiento como paso necesario para la liberación de las acciones, una liberación cuyo objetivo es la tarea siempre en proceso de la búsqueda de la autonomía, entendida esta como la asunción de nuestro propio poder instituyente.

Antes de finalizar esta primera parte de nuestro trabajo, es necesario aclarar a qué se refiere al autor cuando nos habla de significaciones y resignificaciones, pues es aquí donde aparece una de sus propuestas centrales, aquella de las significaciones imaginarias sociales. Para Castoriadis, la institución de la sociedad es "inconcebible sin la significación" (2008b:II, 91), y cuando habla de significación, se refiere a esa búsqueda de sentidos siempre latente en la existencia del ser, sentidos que encontramos en lo que él llama las significaciones imaginarias sociales, es decir, un mundo de significaciones posibles que nos ofrece la misma sociedad, y que se despliegan en dos dimensiones: la dimensión conjuntista-identitaria y la dimensión imaginaria propiamente dicha. La primera es aquella en la que la sociedad opera a partir de elementos, clases, propiedades, relaciones establecidas como distintos y definitivos, es decir, es la dimensión de la existencia como calidad de lo determinado, una dimensión que se hace sentir a través del lenguaje mediante el uso de términos aparentemente cerrados en cuanto a las posibilidades de interpretación, un cerramiento que para Castoriadis está "lleno de poros" (2008b:II, 85). A diferencia de la dimensión conjuntista identitaria, la dimensión imaginaria refiere a las significaciones, es aquella en la que la existencia es significación, y en la que las significaciones no están determinadas. En palabras del autor, "las instituciones están hechas de significaciones socialmente sancionadas y de procedimientos creadores de sentidos. Estas significaciones son esencialmente imaginarias $-\mathrm{y}$ no racionales, funcionales o reflejos de la realidadson significaciones imaginarias sociales", las cuales serán efectivas siempre y cuando sean "investidas y vivenciadas con fuerza" por nosotros los seres humanos (Castoriadis, 2008b:II, 38). ${ }^{10}$ Con lo anterior, deja ver Castoriadis la necesidad de cuestionarnos sobre la raíz de las significaciones que nos rigen, sobre su conveniencia, y sobre la necesidad de desechar aquellas que limitan nuestra libertad y, por lo mismo, el ejercicio de nuestro proyecto de autonomía. Como señala Rafael Miranda, "las certezas incuestionables, las verdades eternas y las metanormas, que sustentan la heteronomía social, pertenecen a otro orden. En nada se parecen al lugar de la deliberación radical y en consecuencia, por definición y principio involuntario, van a contracorriente del proyecto de la sociedad autónoma" (Miranda, 2008:109).

Consideramos pertinente complementar lo dicho hasta este punto con otro planteamiento esencial en Castoriadis, vinculado directamente con el proyecto de autonomía y ligado al tema que nos atañe: el proceso creativo. Nos referimos a la imaginación radical, que es la "capacidad de la psique de crear un flujo constante de representaciones, deseos y afectos. Es radical en tanto es fuente de creación. Esta noción se diferencia de toda idea de la imaginación como señuelo, engaño, etc., para acentuar la poiesis, la creación" (Castoriadis, 2008b:I, 183). Es esta imaginación radical la que, como "capacidad de crear nuevas representaciones independientes del imaginario instituido", posibilita la ruptura del cerco de significaciones provenientes de la sociedad — las significaciones imaginarias sociales - (Aldegani, 2016:73). Esta imaginación radical es la potencia creativa que surge de la facultad espontánea de representación, no atada a un fin predeterminado, que es propia del psiquismo humano. En palabras del autor "no se trata simplemente de ver - o de verse - en un espejo, sino también de la capacidad de dar forma a lo que no está ahí, de ver en algo lo que no está presente" (Castoriadis, en Martínez, 2014:11). 


\section{Ventana al caos o la visión castoridiana del arte}

La obra de arte sólo existe suprimiendo lo funcional y lo cotidiano, develando un reverso que destituye cualquier significación del Lugar habitual, creando un desgarramiento por el que vislumbramos el Abismo, el Sin fondo sobre el que vivimos constantemente aunque hagamos esfuerzos por olvidarlo

(Castoriadis, 2008a:137).

La propuesta de Castoriadis sobre el arte toma como punto de partida su visión del ser como Caos y Cosmos, y considera que en los seres humanos se da un ocultamiento de este Caos y este Cosmos por la institución social y por la vida cotidiana. Es aquí donde entra en juego el arte, más específicamente - en palabras del autor-, "el gran arte", pues por medio de este último el creador hace posible el "develamiento" de ese caos (Castoriadis, 2008a:110). En otras palabras, nos habita una desazón, un desasosiego, un "caos", y el artista, a través de sus creaciones, logra sacarlo a flote, correr el manto detrás del que se esconde para hacerlo visible. Castoriadis define el caos como abismo, como aquello que no tiene fondo, y como acabamos de señalarlo, define también al ser como caos, y este caos, que para el autor es ausencia de sentido, le acompañará constantemente, presentándose ante la psique de una u otra forma, pero siempre como una búsqueda constante de sentido (Castoriadis, 2008b:I, 173). ${ }^{\text {Il }}$ Sin embargo, el ser humano sobrevive a este caos a partir del proceso de socialización, que le permite a la psique una identificación indirecta con la forma social del individuo, una forma alternativa de significación - no del todo satisfactoria - construida a partir de los sentidos que la sociedad le ofrece, es decir, a partir de lo que Castoriadis denomina como las significaciones imaginarias sociales. No obstante, señala el autor, que por estructurado y sólido que sea el individuo socialmente fabricado, no dejará de ser "más que una película que recubre el caos [...] de la psique" (Castoriadis, 2008b:I, 173). En otras palabras, bajo este enfoque vivimos en un estado permanente de negación del caos, el cual sobrellevamos soportados en un proceso continuo de significación y resignificación.
Retomando el papel del arte en el descubrimiento del caos según lo plantea Castoriadis, surge la pregunta: ¿de qué manera se produce ese develamiento del caos? Se da por medio de un "dar forma" que se concreta en la "creación de un cosmos", la creación de "todo un mundo", un mundo que nadie conocía ni había visto jamás (2008a:111-112). Dice Castoriadis que, bien puede ser en la pintura, la literatura, la danza, la música, la arquitectura, la gran obra "hace ver algo que estaba ahí pero que nadie veía; y que al mismo tiempo hace existir eso que nunca ha estado ahí y que sólo existe, precisamente, en función de la obra de arte" (Castoriadis, 2008a:112). Ejemplifica con obras arquitectónicas como el Partenón, Chartres, Reims o Colonia; pinturas como El monumento a los pájaros de Max Ernst y novelas como El castillo de Kafka. Detenido en esta última, amplía su exposición señalando que "[n] adie ha vivido en un mundo como ese, y todos hemos vivido en ese mundo" una vez que la hemos leído, y añade que "la creación es esto" (Castoriadis, 2008a:112).

Un mundo nuevo y distinto armado con trozos de la realidad cotidiana, pero más real que aquel del cual brota por acción del artista, ¿cuál mundo es ese? Es el mundo del caos, el abismo, el sin fondo, lo que para Castoriadis quiere decir, "lo que está detrás, o debajo de toda existencia concreta" (Castoriadis, 2000:199), es decir lo que está bajo el recubrimiento del ser resultante del proceso de socialización, lo que siempre está allí, la psique indómita que "nunca deja, bajo una forma u otra, de anunciársele y estar presente"; pero además de este caos - psíquico- que enfrenta el ser humano, está también el Caos, el Abismo, el Sinfondo del mundo (Castoriadis, 1984:4-5). Ese es el cosmos que puede verse en la obra artística; el "gran arte" del que habla Castoriadis - arte que es rasgadura del revestimiento del ser-, un mundo que aflora allí para convertirse en experiencia del sentido, el momento del sentido, un momento único e individual que quisiéramos nunca se detuviera y que no es posible traducir en palabras, una "combinación de alegría y tristeza, de placer y de duelo, de asombro sin fin y de asentimiento..." (Castoriadis, 2008a:123-125). 


\section{Débora Arango o el "develamiento" del caos}

Después de habernos acercado a los planteamientos de Castoriadis se hace inevitable pensar en Débora Arango en términos de una existencia marcada por aspectos como: la lucha permanente en favor de la autonomía individual en un medio caracterizado por la heteronomía; la defensa de lo imaginario radical siempre en confrontación con la sociedad instituida y sus significaciones imaginarias sociales; el cuestionamiento de la norma heredada - lo impuesto - que determina el modo hacer, pensar y sentir; la ruptura de la estabilidad como búsqueda de lo verdaderamente otro - la alteridad-, por la autoconstitución y la autotransformación; el enfrentamiento con la religión -ocultadora del caos-, en este caso la fe católica que Arango comparte como creyente; y ante todo la creación, su arte como medio, como apertura a nuevos universos de sentido y significación que posibiliten la confrontación con el caos/abismo/sin fondo que como mundo propio nos acompaña desde el inicio de nuestra existencia. Dicho de otra manera, Débora Arango y su obra ejemplifican esa tensión permanente entre la psique "socializada" — en permanente estado de agitación-y la sociedad perpetuadora de significaciones que garantizan su cohesión y estabilidad.

El punto de partida del recorrido de Arango en favor de la autonomía lo marca la determinación de consagrar su vida al arte. Luego vendrán decisiones en el proceso de formación y despliegue de su obra, que confirman su talante resuelto y que anticipan que en su trabajo podrían darse rupturas del canon plástico imperante en su entorno. Nos referimos, en primer lugar, a su determinación de poner fin a las clases con el maestro Eladio Vélez, una acción motivada en su aburrimiento por la práctica a partir de la copia que busca la fidelidad versus su interés por la creación ajena a la exactitud fotográfica; y en segundo lugar, a su decisión de ir en busca del maestro Pedro Nel Gómez como su nuevo mentor, dado que en sus pinturas veía creación, fuerza, movimiento, colorido, un encuentro con "algo que hasta entonces desconocía, algo que no había tenido ocasión de comprender" y que le abría "un nuevo y amplio campo de realización" que llenaba el vacío que sentía (Instituto
Cultural Cabañas, 2008:9; Londoño, 1997:46; Laverde y Rojas, 1986:42-43). La formación con Gómez sería decisiva no solo por su influencia en la búsqueda de un estilo propio, sino también porque con él se iniciaría en el trabajo del desnudo, un tema que consideramos permite a Arango nuevas oportunidades para manifestar y defender, desde su interés primario, la pintura, su postura - afirmativa - ante la alteridad.

Aunque su estilo producía rechazo en algunos sectores de la sociedad, las críticas y descalificaciones más fuertes que recibió la obra de Débora Arango provenían esencialmente a causa de sus desnudos, y las razones de la molestia tenían que ver con aspectos como: 1) que fueran realizados por una mujer; 2) que su tratamiento del cuerpo humano no coincidiera con el refinamiento, la perfección y las poses propias del canon imperante con el que el medio estaba familiarizado; 3) que en ellos apareciera la mujer activa que enfrenta el mundo real; 4) que estos cuerpos —más allá de lo puramente pictórico - ofrecieran una ocasión para pensar, que fuera evidente que las formas y colores conducían a un hacer-ver aspectos de la realidad cotidiana, y 5) que la sexualidad, el placer y el erotismo dejaran de ser temas vedados y se presentaran sin rodeos desde la mirada y la órbita de la mujer.

El recuento de motivaciones vinculadas con las críticas a los desnudos en la pintura de Débora Arango nos remite a aspectos relacionados con la tradición -en este caso, de la conservadora sociedad antioqueña de la primera mitad del siglo XX-; con la cultura patriarcal: la pintura de desnudos es aceptable siempre que sea hecha por el hombre, y además desde la mirada del hombre, cultura que también le impide a la mujer contemplarse a sí misma, encontrarse con ella misma y darse el tiempo y el espacio para la intimidad y la exploración del propio cuerpo; con la norma estética: el canon academicista europeo heredado - promotor del idealismo-; con la moda de la época en el arte regional y nacional: la mirada idílica hacia el paisaje y la naturaleza; con las normas de urbanidad y el decoro exigidas en condiciones de desigualdad: la mujer educada como símbolo de prudencia, delicadeza, belleza, recato, pudor; con la injerencia de la ideología y la religión en la 
vida de las personas: Débora, mujer artista inmersa en un debate de corte moralista atravesado por el levantamiento de banderas ajenas a su quehacer. ${ }^{12}$

El inventario que hemos realizado permite pensar a Débora Arango y su obra como inmersas en un mar de trabas que se intersectan en múltiples direcciones, en términos de Castoriadis, una "urdimbre inmensamente compleja de significaciones" que rigen la vida de la sociedad heterónoma y a sus individuos, a saber, las significaciones imaginarias sociales que la sostienen, aquellas que confronta Débora Arango en el ejercicio individual de su capacidad de devenir autónoma.

Castoriadis dice que no hay una mejor caracterización de las sociedades heterónomas que "la rigidez de las investiduras", y añade más delante que en "una sociedad heterónoma lo que está instituido es sagrado; esto significa también: no se lo puede tocar; y esto significa aún: usted lo inviste, si no, usted es un monstruo, un criminal, anormal, asocial, secuaz de Satán, etcétera" (Castoriadis, 2004:132-135). En otras palabras, este tipo de sociedades, y en general las sociedades, funcionan "en una clausura que tiende a perpetuarlas y permiten sólo cambios (imperceptibles o sólo visibles en períodos de tiempo muy largos) que no las perturben radicalmente" (Malaver, 1999:252).

Débora Arango decide rebelarse ante las significaciones imaginarias sociales de su sociedad, aquellas que la oprimen; tal vez emerge en ella esa fracción de la psique que para Castoriadis no renuncia del todo al autoinvestimiento y que le permite asumir el rechazo de los contenidos social-históricos. Débora Arango se atreve a tocar lo intocable por la vía de la resignificación de las formas.

Veamos de qué manera lo dicho, y en general el planteamiento de Castoriadis sobre el arte como ventana al caos, puede ejemplificarse con el trabajo de Arango. Iniciaremos con un análisis simultáneo de dos obras que abordan lo que pareciera ser una misma preocupación, La mística (1940) y La huida del convento (1950), luego comentaremos Sin título (1944).

En La mística (ver Imagen 1) y en La huida del convento (ver Imagen 2) se combinan aspectos como el desnudo, la mujer y lo religioso, todos ellos de la esencia del trabajo de Arango, y además con rasgos formales que abonan a lo ya anotado en nuestra aproximación a la comprensión de la pintora y su obra desde los planteamientos de Castoriadis.

En ambos casos, estas pinturas muestran en primer plano a una mujer desnuda en actitud que sugiere, en el primer caso, una postura meditativa, y, en el segundo, un inicio de movimiento hacia la acción. El contexto luce muy similar: adelante, un vano que es apertura hacia un exterior que hace visibles los cuerpos de estas mujeres; a sus espaldas, representaciones que aluden a lo religioso, esto es, en el primero, una espadaña rematada con una cruz - típica de lo que puede ser la fachada un templo católico-, y en el segundo, bajo un arco, tres figuras religiosas con trajes oscuros que contrastan con la luz del cuerpo femenino del primer plano. Todo en el primer plano es descubrimiento: el cuerpo que se destapa, que se deja ver sin tapujos (más en el segundo caso que en el primero, tal vez una muestra de la evolución del estilo hacia uno más libre, más desenvuelto, más audaz), la duda que se resuelve y da paso a la acción que libera, el salto hacia el mundo en busca de nuevos horizontes de sentido, el adiós a la clausura: la apertura. Atrás queda el mundo religioso y sus restricciones. Allá afuera estará la posibilidad de la autonomía, o del encuentro con nuevas maneras de evadir el caos: otras significaciones instituidas.

En términos de Castoriadis, podríamos ver en estas imágenes a la mujer sujeto que, insatisfecha con la significación que la religión da a su ser, decide encarar el caos que la habita e intenta al mismo tiempo liberarse de su fe, uno de tantos simulacros instituidos como ocultamiento del abismo del mundo externo y del propio, asumiendo la confrontación de las significaciones imaginarias sociales en las que su vida se desenvuelve. ${ }^{13}$

Débora Arango pareciera con estas obras, desde la creación, realizar el mismo ejercicio de sus protagonistas. A partir de la mímesis como medio, da origen a un cosmos que es develamiento del abismo que le habita, un mundo que desgarra las evidencias cotidianas y que pone en cuestión a la sociedad instituida, y que, además, se presenta como una forma que posibilita la deliberación en torno a lo dado. Aparece aquí resaltada por Arango 
la polaridad planteada por Castoriadis entre el arte y la religión: "el gran arte es a la vez la ventana de la sociedad al caos, y la forma dada al caos (mientras que la religión es la ventana al caos, y la máscara puesta sobre el caos)" (2008b:II, 137). Con trabajos como estos, la pintora pareciera querer abrir la posibilidad de remover una de esas máscaras que ocultan el abismo, la que ofrece la religión, una osadía que pagaría con la descalificación de su trabajo, y en el contexto religioso con la amenaza de excomunión. ${ }^{14}$ Recordemos que en la institucionalidad religiosa la protección ante el cuestionamiento está blindada toda vez que la ley proviene de un ser superior que está más allá de los seres humanos vivos (Castoriadis, 2008a:37). Débora y sus mujeres intentan darse su propia ley.

Por último, nos detendremos a continuación en la obra Sin título de 1944 (ver Imagen 3), pintura en la que aparece una pareja de pie en un escenario que no puede relacionarse con nada en concreto, dos personas adelante de un fondo neutro, sin referencias espaciales ni temporales. Así como no hay un título, tampoco hay más elementos que pongan en situación a estos individuos, ese pareciera ser el interés de Arango, resaltar la soledad que les acompaña, allí están ellos, solos, cargando cada uno con su humanidad.

La mujer va adelante, el hombre parece ir con ella, detrás, muy cerca. Nada de esto involucra de manera contundente al espectador, este cometido corre por cuenta de las miradas, turbulencia de la que nadie que esté frente a la pintura puede escapar. Hay allí un contraste profundo. Mientras la mirada de él parece perdida denotando un cierto ensimismamiento, la de ella pareciera reflejar una compleja mezcla de sentimientos que finalmente afloran como una desazón infinita, una ira retenida, la irritación ante el observador indolente. En esos ojos no hay ternura, no hay indiferencia, hay un ser que nos mira y nos confronta. Pareciera que estuviéramos frente a dos mundos; uno, el del individuo que sumido en el conformismo sobrelleva su vida, su caos, y transita por el universo mimando resignadamente un letargo intrascendente; el otro, el mundo de ella, en el que de manera incontenible pareciera asomarse la confrontación con el abismo castoridiano.
Desde la óptica de Castoriadis, podemos pensar que esta obra puede remitirnos de otro modo a ese develamiento del sinfondo que posibilita el arte, lográndolo de manera notable con un recurso: el manejo de la mirada. Pareciera que nada fue suficiente para mantener ignorado el abismo — de la propia psique, del mundo, de la sociedad-,y que solo los ojos cerrados podían ocultarlo hacia el exterior; pero aparece Débora Arango y con su pincel los abre sin preguntar y rasga de una vez y para siempre esa capa que permitía — desde el borde del abismo en que se vive - evadir la mirada al sin fondo en la noche más oscura. Débora se empeña una vez más en desgarrar desde el arte el recubrimiento del ser.

No es esta la única obra de Arango en la que la mirada pareciera remitirnos a esa confrontación con aquella turbulencia del mundo interior, que puede tener origen en una psique que de alguna forma permanece en estado no socializado por cuenta de su resistencia a la renuncia completa del autoinvestimiento, según lo planteado por Castoriadis. Esta ventana al caos puede ser también la que, desde distintos escenarios, abre Arango en piezas como Desnudo (Ca. 1940), La colegiala (1942), Amargada (1944), La filósofa (1950), La Celestina (Ca. 1952) y Paz (1957). ${ }^{15}$

\section{Reflexión final}

A la luz de la propuesta de Cornelius Castoriadis, la vida de Débora Arango pareciera remitirnos a la del individuo particular que se decide a enfrentar el malestar, la interrogación permanente que, en la intimidad, le acompaña en relación con el mundo propio y el mundo que le rodea. Ella, como individuo socializado que es, asume el ejercicio de su capacidad instituyente y se arriesga - buscando su propia autonomía - a poner en tela de juicio lo dado, a controvertir significaciones imaginarias instituidas por la sociedad antioqueña y colombiana de la primera mitad del siglo XX.

Sería exagerado decir que Arango lo confronta todo, pues no en todas las dimensiones de su propia vida es manifiesto el enfrentamiento con el imaginario social, pero desde el ámbito del arte, desde la potencia creativa que es la imaginación radical, pareciera que encuentra Arango una posibilidad de desacralizar lo instituido, lo 
comúnmente aceptado como modo de ser de las cosas, y es por esta vía que se aventura a cuestionar la estética, la Iglesia, el gobierno, la ley, la justicia, el poder militar, los partidos políticos y sus líderes, los tabúes. Pareciera que aquella mujer cosmopolita de modales finos y delicados, conservadora en sus costumbres y que se mantiene firme en su fe católica, se debatiera permanentemente en un dilema similar al de las religiosas de sus pinturas: la vida en clausura o la apertura al mundo exterior; en otros términos, podríamos pensar en una Débora reposada que experimenta una disputa constante entre la vida que lleva — con malestar interior por la clausura del sentido y la significación instituidos-y la posibilidad de afrontar la autoinstitución, la interrogación que abre paso a nuevos sentidos. Es en la creación de nuevos mundos — cosmos - que posibilita el arte, en la pasión de su vida: la pintura, donde al parecer encuentra un modo de realizar su propia libertad, una manera de encarar y darle forma al caos humano, a su abismo. No será esta una libertad efectiva plena en tanto se realiza en medio de una sociedad heterónoma, pero, por esta vía de las formas, Débora Arango abre la posibilidad de modificaciones en el dominio de lo histórico-social, la más importante de ellas: el inicio de una revolución estética en el arte colombiano del siglo XX.

\section{Notas}

${ }^{1}$ Eladio Vélez y Pedro Nel Gómez, los maestros de Débora Arango en su natal Antioquia, representaban en su momento dos tendencias artísticas opuestas que dieron lugar a pugnas entre seguidores y críticos de uno y otro bando. Los "pedronelistas" catalogaban a los "eladistas" como "reaccionarios", "capitalistas" y "filisteos", y los pedronelistas eran señalados por sus contradictores como promotores de una pintura "revolucionaria" y “antiburguesa” (Londoño, 1985:4). Arango se formó entre estas dos corrientes. Pueden vislumbrarse aquí parte de los cambios que el arte estaba experimentando en el contexto local: por un lado, el apego a la tradición representada por la academia y su preocupación por la belleza, y por el otro, el rechazo a la academia y sus cánones, el interés nacionalista y la búsqueda de lo propio, así como la inclusión de temas de corte social (Londoño, 2001:225-247).

${ }^{2}$ La injerencia de la Iglesia católica en la política, la educación, la sociedad y los asuntos del Estado en Colombia, es un tema de vieja data, que tuvo posibilidades de cambio con las reformas liberales de mediados del siglo XIX, las cuales llegaron a su fin con el inicio de la hegemonía conservadora (1886) y con la firma del Concordato con El Vaticano en 1887. Al finalizar el siglo XX, a partir de la Constitución de 1991, esta situación empieza a evidenciar signos efectivos de delimitación (Palacios, 2003).

${ }^{3}$ Es amplio el número de pinturas en las que la época vivida permea la búsqueda plástica de Arango. Resaltamos entre ellas Los derechos de la mujer (1954), una clara alusión a la aprobación del derecho al voto femenino en Colombia en 1954, hasta ese momento, uno de los derechos civiles negados a la mujer. Entre otros trabajos de Arango asociados a lo que pasaba en Colombia, podemos señalar, por ejemplo: El tren de la muerte (1948), Masacre del 9 de abril (1948), 13 de junio (1953), Rojas Pinilla (1954), Huelga de estudiantes (1954), Junta militar (1957), La República (1957) y El cementerio de la chusma y/o mi cabeza (1958), todos ellos con evidente tono sarcástico y acento en la crítica política, la denuncia social y el desafío al poder.

${ }^{4}$ En entrevista con Kathya Jemio Arnez, Débora Arango rememora las reacciones que sus primeros desnudos provocaron en aquella exposición del Club Unión. Este documento recorre varios pasajes de la vida de la artista y explora con ella la inspiración que orientó algunas de sus obras (Jemio, 2006).

${ }^{5}$ El texto de Santiago Londoño Vélez —Débora Arango. Vida de pintora (1997) - es probablemente el más completo y documentado recuento de la vida de la artista y su trabajo. También pueden verse: Galeano (2005), Zuluaga (2011) Londoño (2011) y MAMM (2012).

${ }^{6}$ El catálogo de la exposición retrospectiva de 1984 reproduce los comentarios virulentos que en diferentes medios aparecieron para descalificar la obra de Arango, como también las críticas y comentarios favorables (MAMM, 1984). Sobre los comentarios de Marta Traba (1930-1983), la voz dominante en la crítica artística colombiana entre los años cincuenta y setenta, puede verse Londoño (1997:205). 
7 Tras quince años retirada de las salas, en 1974 Débora Arango participa nuevamente en una exposición, esta vez en el Museo de Arte Moderno de Bogotá, una muestra titulada Arte y política que marca el inicio de una nueva etapa para su obra. Otras exposiciones en los años subsiguientes posibilitan nuevas miradas a su trabajo. Será el año de 1984 el que marca una ruptura en su posicionamiento, pues además de recibir el premio de las Artes y las Letras de la Secretaría de Educación y Cultura de Antioquia, el Museo de Arte Moderno de Medellín lleva a cabo una gran exposición retrospectiva (19371984) a la que le siguen otras en los escenarios más reconocidos del arte en Colombia (MAMM, 2012:159-163).

${ }^{8}$ En un trabajo previo nos hemos detenido en el análisis de la propuesta de Arango (Gómez, 2018).

${ }^{9}$ En este recorrido - en extremo condensado- por el pensamiento de Cornelius Castoriadis, además de en la bibliografía citada, nos apoyamos en la información recibida en el seminario "Sociedad instituyente y clínica de la alteridad. Un cercamiento a la obra institucional de Cornelius Castoriadis" (Miranda, 2014).

${ }^{10}$ Ejemplos de significaciones imaginarias sociales según Castoriadis son: "espíritus, dioses, Dios, polis, ciudadano, nación, estado, partido, mercancía, dinero, capital [...] tabú, virtud, pecado, etc. pero también hombre/mujer/hijo según están especificados en una determinada sociedad" (2008b:I, 166).

${ }^{11}$ En Sujeto y verdad anota Castoriadis: "el Caos excluye el Saber absoluto, el kósmos permite cierto saber sobre el mundo, porque, con todo, allí reina cierto orden. Pero como ya he dicho, Caos es también la ausencia de significación desde el punto de vista del ser humano" (2004:311).

${ }^{12}$ Para ahondar en las rupturas de Arango en el tratamiento del cuerpo femenino puede verse Giraldo (2010). La autora explora cómo, a partir de la obra de la pintora, se da inicio a un cambio radical en la representación del cuerpo de la mujer en el arte colombiano: la mujer deja de ser mirada para mirarse a sí misma.

${ }^{13}$ Para Castoriadis, "la religión responde a la incapacidad de los humanos de aceptar lo que se ha mal llamado 'trascendencia', es decir, de aceptar el Caos y de aceptarlo como Caos, de afrontar de pie el Abismo"; en tal sentido, "en su efectividad social la religión proporciona y debe siempre proporcionar simulacros instituidos del Abismo" (Castoriadis, 1984:8).

${ }^{14}$ En una sociedad tradicionalmente católica como la colombiana, en donde este credo - de la mano del Estado- históricamente ha formado parte del andamiaje social e institucional, una afrenta como la de Débora, realizada en la primera mitad del siglo XX, era un agravio a buena parte de la sociedad.

${ }^{15}$ Limitaciones de espacio hacen imposible incluir todas las imágenes referidas en el texto. Algunas de estas pinturas pueden apreciarse en la página del Museo de Arte Moderno de Medellín. Véase https://www.elmamm. org/Colecci\%C3\%B3n/Colecciones?AutorID=28\&Title $=\mathrm{D} \% \mathrm{C} 3 \%$ A 9 bora\%20Arango

\section{Referencias}

Aldegani, Emiliano (2016). Ontología y política. Análisis y observaciones de la filosofía de Cornelius Castoriadis. Tesis de posgrado, Universidad Nacional de La Plata-Facultad de Humanidades y Ciencias de la Educación. Disponible en: http://www.memoria.fahce.unlp.edu. ar/tesis/te.1266/te.1266.pdf (consultado el 26 de mayo de 2020).

Castoriadis, Cornelius (1984). "La institución de la sociedad y la religión” (Ida Vitale, trad.). S.p.i. Disponible en https://arditiesp.files.wordpress.com/2012/10/castoriadis_instit_soc_relig_1984.pdf (consultado el 4 de mayo de 2020).

Castoriadis, Cornelius (2000). Figuras de lo pensable. València: Universitat de València.

Castoriadis, Cornelius (2004). Sujeto y verdad en el mundo histórico-social (Sandra Garzonio, trad.). Buenos Aires: Fondo de Cultura Económica. Disponible en https://revolucioncantonaldotnet.files.wordpress. com/2018/02/castoriadis-cornelius-sujeto-y-verdaden-el-mundo-historico-social.pdf (consultado el 14 de mayo de 2020)

Castoriadis, Cornelius (2008a). Ventana al caos. Buenos Aires: Fondo de Cultura Económica.

Castoriadis, Cornelius (2008b). El pensamiento de Cornelius Castoriadis, 2 t. S.I.: Ediciones Proyecto Revolucionario. 
Galeano, Ángel (2005). Débora Arango. El arte venganza sublime. Bogotá: Panamericana.

Giraldo Escobar, Sol Astrid (2010). Cuerpo de mujer: modelo para armar. Medellín: La Carreta Editores.

Gómez Prada, Jaime A. (2018). Tres propuestas plásticas en el arte colombiano del siglo XX: Débora Arango, Beatriz González y Doris Salcedo. Convergencias y divergencias. Tesis doctoral, Centro de Estudios Superiores de México y Centroamérica (CESMECA), Universidad de Ciencias y Artes de Chiapas. Disponible en https://repositorio.cesmeca.mx/bitstream/handle/11595/972/TESIS\%20DOCTORAL.\%20Jaime\%20 G\%c3\%b3mez.pdf?sequence=1\& $\&$ is Allowed=y (consultada el 29 de mayo de 2020).

Instituto Cultural Cabañas (2008). Débora Arango, una revolución inédita del arte colombiano. Catálogo de exposición, Feria Internacional del Libro de Guadalajara, 22 de noviembre de 2007-15 febrero de 2008.

Jemio Arnez, Kathya (2006). “Débora Arango. La transgresora de los signos de 1939. (1907-2005)". En Revista Lasallista de Investigación, 3(2), julio-diciembre, 62-73, Corporación Universitaria Lasallista, Antioquia, Colombia. Disponible en https:/www.redalyc.org/pdf/695/6953021l.pdf (consultado el 10 de enero de 2021).

LaRosa, Michael y Germán Mejía (2013). Historia concisa de Colombia (1810-2013). Bogotá: Ministerio de Cultura de Colombia, Pontificia Universidad Javeriana, Universidad del Rosario.

Laverde Toscano, María Cristina y Álvaro Rojas (1986). Así hablan los artistas. Bogotá: Fundación Universidad Central.

Londoño Vélez, Santiago (1985). "Paganismo, denuncia y sátira en Débora Arango". En Boletín Cultural y Bibliográfico, XXII(4). Bogotá: Banco de la República.

Londoño Vélez, Santiago (1997). Débora Arango. Vida de pintora. Bogotá: Ministerio de Cultura República de Colombia.

Londoño Vélez, Santiago (2001). Arte colombiano 3500 años de historia. Bogotá: Villegas Editores.

Londoño Vélez, Santiago (2011). Débora Arango. Cuaderno de notas. Medellín: Tragaluz.

Malaver, José (1999). "Emergencia, creación y autonomía en la ontología de Castoriadis". En Ensayo y
Error. Revista de Pensamiento Crítico Contemporáneo, 6(4), junio.

MAMM (Museo de Arte Moderno de Medellín) (1984). Débora Arango. Exposición Retrospectiva 1937-1984 [catálogo de exposición]. Medellín: MAMM.

MAMM (Museo de Arte Moderno de Medellín) (2012). Débora Arango llega hoy. Medellín: MAMM.

Martínez Román, Adi Gloria (2014). El proyecto de autonomía en Cornelius Castoriadis: Importancia de la imaginación radical y la democracia como forma de vida para la liberación humana. Tesis doctoral, Instituto Bartolomé de las Casas de Derechos Fundamentales, Universidad Carlos III, Madrid. Disponible en https://e-archivo.uc3m.es/handle/10016/18997 (consultado el 26 de mayo de 2020).

Medina, Álvaro (s.f.). "La renovación vanguardista, 1910-1950". Bogotá: Red Cultural del Banco de la República. Disponible en http://www.banrepcultural.org/coleccion-de-arte-banco-de-la-republica/ la-renovaci\%C3\%B3n-vanguardista-1910-1950 (consultado el 8 de enero de 2021).

Miranda, Rafael (2008). "Castoriadis y el regreso de lo religioso. Auto-alteración de la sociedad y meta-norma”. En Liminar. Estudios Sociales y Humanísticos, VI(1), junio, 98-113. Disponible en https://liminar.cesmeca. mx/index.php/rl/article/view/269 (consultado el 31 de mayo de 2020).

Miranda, Rafael (2014). "Sociedad instituyente y clínica de la alteridad. Un acercamiento a la obra institucional de Cornelius Castoriadis" [documento inédito]. Seminario en el doctorado en Ciencias Sociales y Humanísticas, Centros de Estudios Superiores de México y Centroamérica-Universidad de Ciencias y Artes de Chiapas, San Cristóbal de las Casas, México.

Palacios, Marco y Frank Safford (2002). Colombia país fragmentado, sociedad dividida. Su historia. Bogotá: Norma.

Palacios, Marco (2003). Entre la legitimidad y la violencia. Colombia 1875-1994. Bogotá: Norma.

Traba, Marta (1985). Historia abierta del arte colombiano. Bogotá: Instituto Colombiano de Cultura.

Zuluaga P., Carolina (ed.) (2011). Débora Arango. Bogotá: Ediciones Gamma. 
Imagen 1. La mística, Débora Arango (1940). Acuarela, 99 x 66 cm

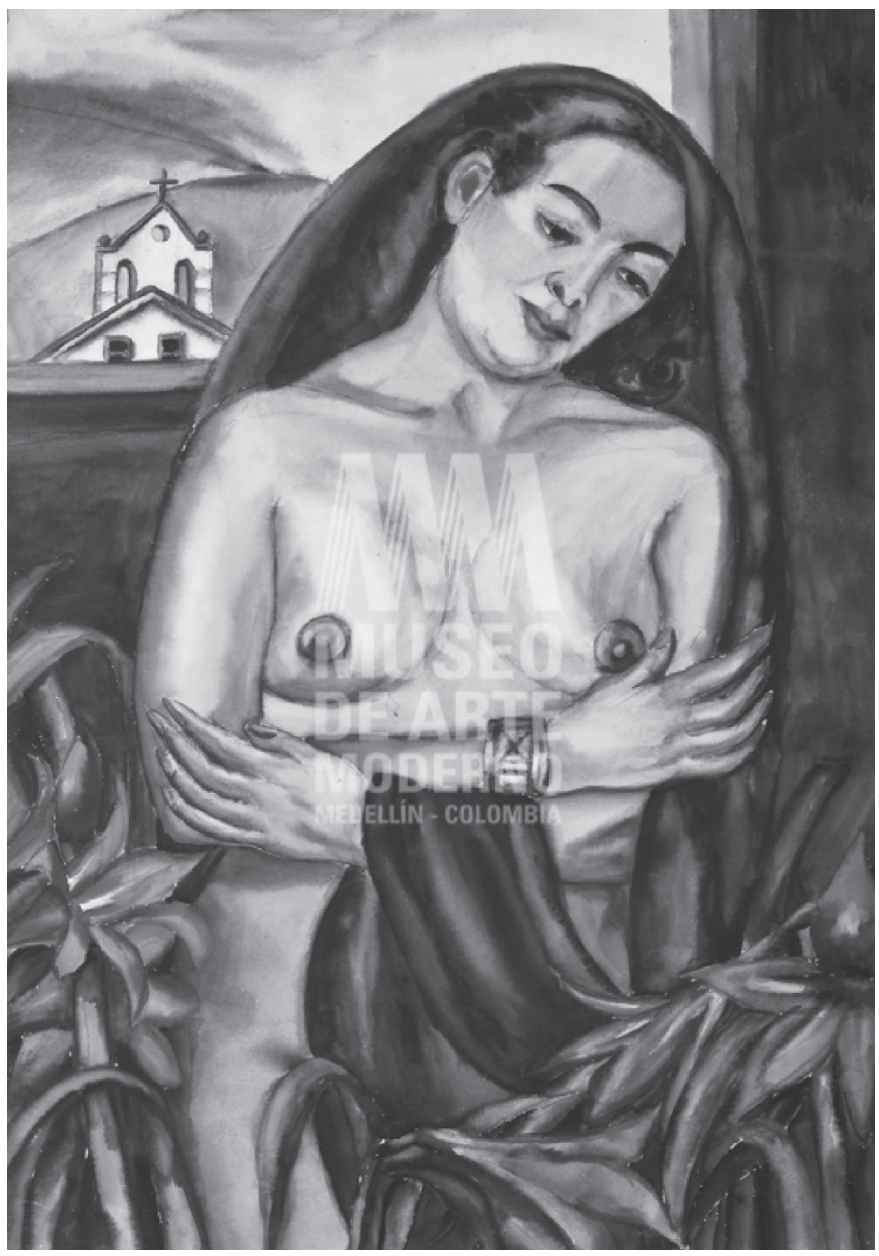

Fuente: Museo de Arte Moderno de Medellín, en https:/www.elmamm.org/Colecci\%C3\%B3n/Colecciones?AutorID=28\&Title=D \%C3\%A9bora\%20Arango (consultado el 31 de mayo de 2020). 
Imagen 2. La huida del convento, Débora Arango (1950). Acuarela, 100 x 67 cm

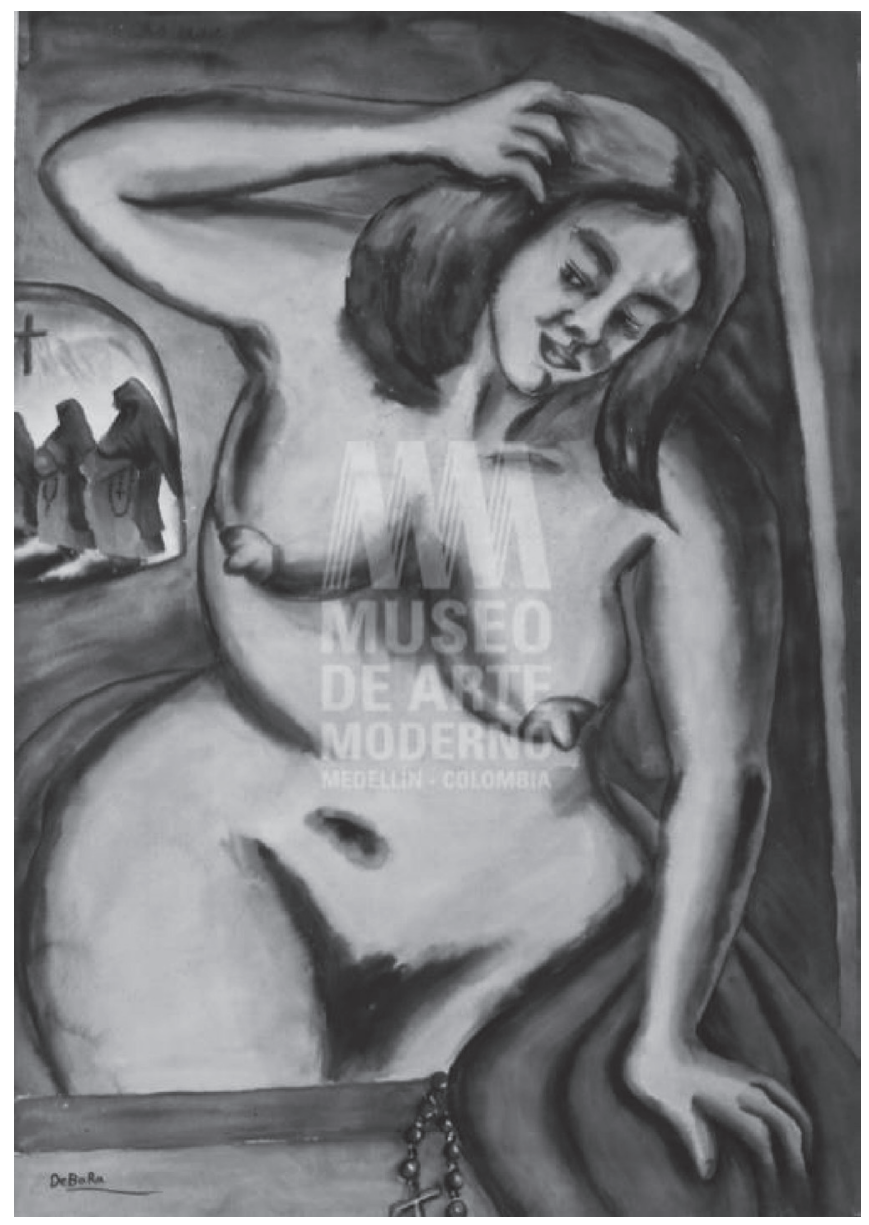

Fuente: Museo de Arte Moderno de Medellín, en: https://www.elmamm.org/Colecci\%C3\%B3n/Colecciones?AutorID=28\&Title=D $\%$ C3\%A9bora\%20Arango (consultado el 31 de mayo de 2020). 
Imagen 3. Sin título, Débora Arango (1944). Acuarela, 84 x 64 cm

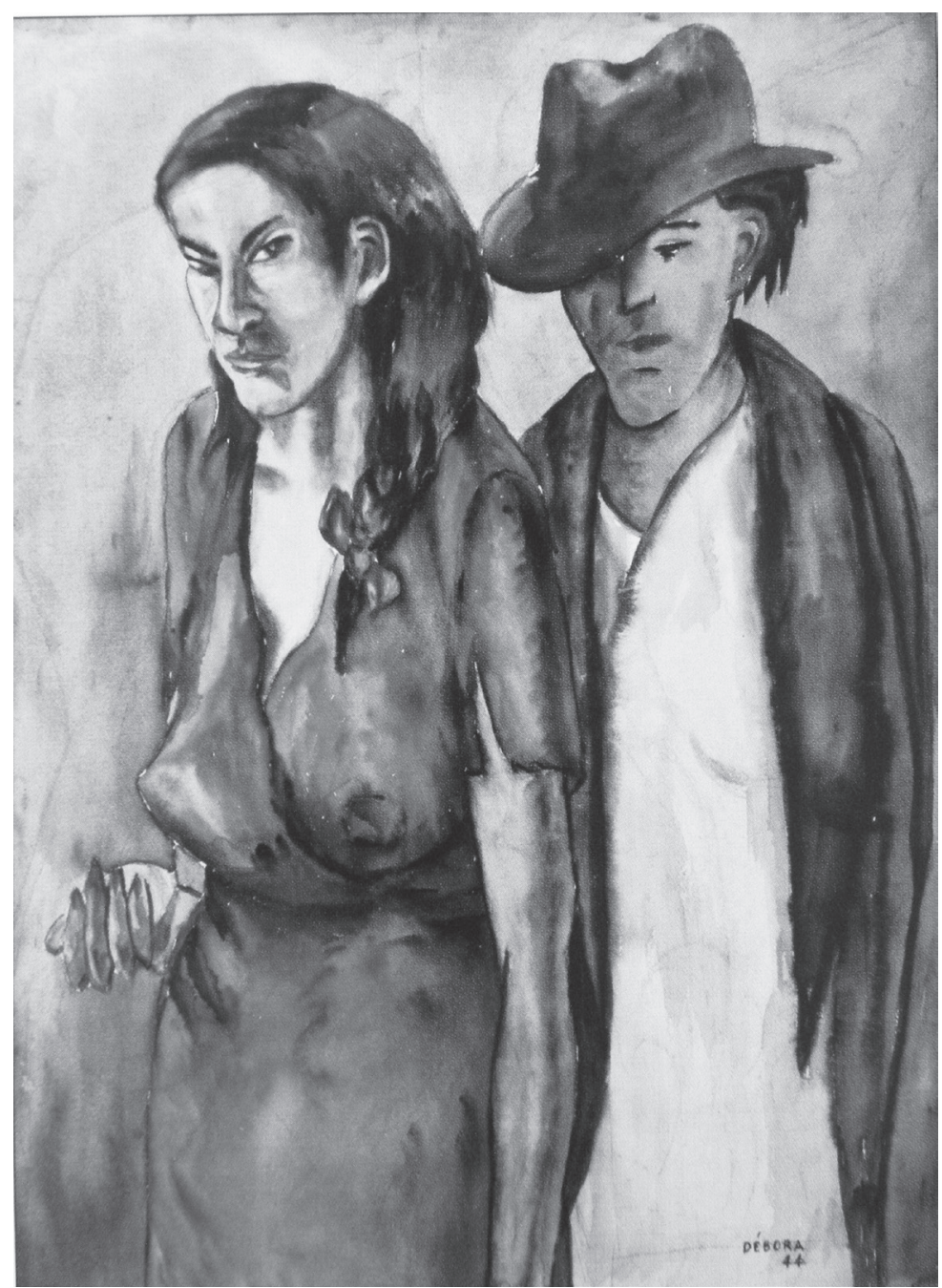

Fuente: Museo de Arte Moderno de Medellín (MAMM, 2012:117). 